\title{
AN ANAESTHETIC SPRAY
}

\section{J. KildufF, M.D.*}

Since topical anaEsthesid may be used at any age, it is desirable to have a spray with interchangeable metal tubes of varying lengths. Experience with many models has indicated that the following features are desirable: the spray must stand upright and be easily seen; the base should not adhere to modern work surfaces; it should be easy to assemble, repair, and sterilize; the metal tube should be detachable and of large bore; and the only perishable part should be a standard rubber bulb.

A spray as illustrated in Figure 1 has been in use for many years by broncho-

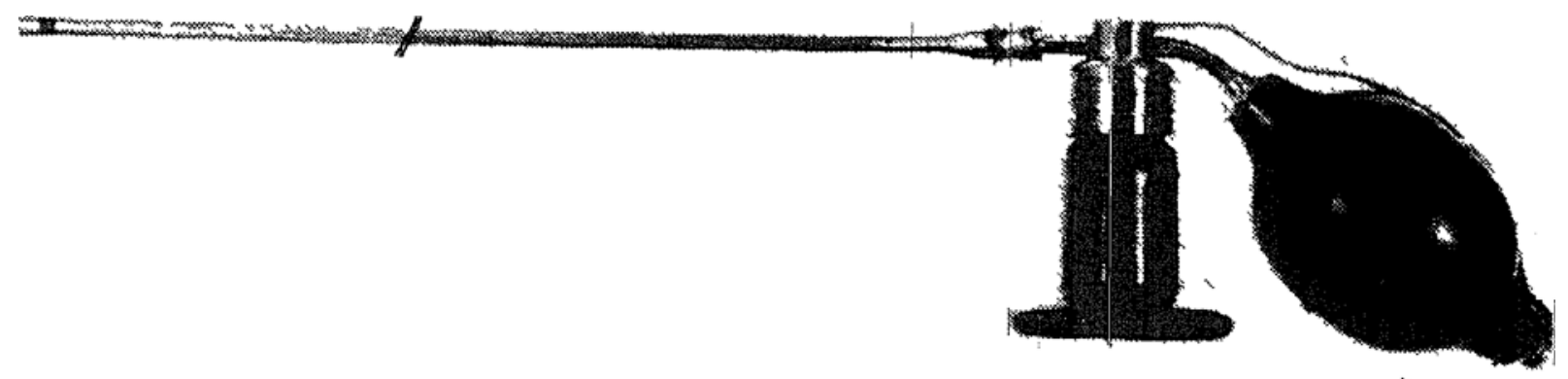

FIGURE 1

scopists for topical anaesthesia and has been very satisfactory. Its original metal tube, $32 \mathrm{~cm}$. in length, was shortened to $22 \mathrm{~cm}$. and proved very satisfactory for adult use. Metal tubes of varying length will now be supplied by the makert on request for adult and paediatric use.

*From the Department of Anaesthesia, University Hospital, Saskatoon, Saskatchewan. †Available from George P. Pilling \& Sơn Co., 3451 Walnut St., Philadelphia 4, Pa.

Can. Anaes. Soc. J., vol. 8, no. 4, July, 1961 